\title{
LANGUAGE-DRIVEN SPATIOTEMPORAL CAUSAL INTEGRATION IN THE PREFRONTAL AND PREMOTOR CORTICES
}

\author{
MODULACIÓN LINGÜÍSTICA DE LA INTEGRACIÓN ESPACIO- \\ TEMPORAL DE LA INFORMACIÓN CAUSAL EN LAS ÁREAS \\ PREFRONTAL Y PREMOTORA DE LA CORTEZA CEREBRAL
}

\section{ROBERTO LIMONGI TIRADO}

Laboratory of Neurophysiology, Venezuelan Institute for Scientific Research rlimongi@ivic.gob.ve

MICHAEL E. YOUNG, Ph.D.

Brain and Cognitive Sciences Program, Southern Illinois University Carbondale meyoung@siu.edu

\section{ABSTRACT}

The behavioral literature has reported the differentiation between perceived causality and higher-order causal reasoning. The advent of modern technology such as functional magnetic resonance imaging and the theoretical framework of cognitive linguistics and behavioral experimental designs have raised new hypotheses and opened new possibilities to address the perceptual and higher-order distinction in causality. In this article, we discuss and integrate recent biological and psycholinguistic work on both perceptual and linguistic representations of causality that challenges the modular view of human causal knowledge. We suggest that linguistic and sensory-perceptual representations of causal events might coexist and interact in the brain. In this sense, whereas previous work proposes that the posterior areas of the brain automatically detect the spatiotemporal structure of visual causal events and that the frontal areas integrate such information in a causal representation, results from our research program suggest that this integration process is language-driven. Two different semantic representations of causative linguistic structures (lexical and periphrastic causatives) might influence cognitive control mechanisms, memory resources, and preparatory motor responses when observers evaluate the causal nature of visual stimuli.

Keywords: Causal reasoning, neural basis of causation, lexical causatives, periphrastic causatives. 


\section{RESUMEN}

La bibliografía conductual ha reportado diferencias entre los procesos de percepción causal y procesos superiores de razonamiento causal. El desarrollo de nuevas tecnologías como la resonancia magnética nuclear funcional, la perspectiva teórica de la lingüística cognitiva y los diseños experimentales conductuales han propiciado nuevas hipótesis y abierto nuevas posibilidades para abordar la diferencia entre percepción causal y razonamiento causal. En este artículo discutimos e integramos los recientes avances biológicos y psicolingüísticos sobre las representaciones perceptuales y lingüísticas de la causalidad que desafían la visión modular del conocimiento causal en el humano. Sugerimos que las representaciones lingüísticas y sensorio-perceptuales de eventos causales podrían coexistir e interactuar en el cerebro. En este sentido, mientras trabajos anteriores proponen que las áreas posteriores del cerebro detectan automáticamente la estructura espacio-temporal de los eventos causales visuales y que áreas frontales integran esa información en una representación causal, los resultados de nuestro programa de investigación sugieren que este proceso es modulado por el lenguaje. Las representaciones semánticas de dos estructuras lingüísticas diferentes (léxica y perifrástica) podrían influir en los mecanismos de control cognoscitivo, los recursos de memoria y las respuestas motoras preparatorias cuando los participantes evalúan la naturaleza causal de los eventos visuales.

Palabras clave: Razonamiento causal, bases neurales de la causalidad, estructuras léxicas causativas, estructuras perifrásticas causativas.

Recibido: 18/11/2010. Aceptado: 14/01/2011

\section{INTRODUCTION}

pprehending the causal structure of the world is essential for survival because 1 it allows individuals to predict and control the environment. In humans, perceiving causality is only one method of obtaining causal knowledge; other causal knowledge includes establishing causal relationships between objects separated in space and time (e.g., history, narrative, science, and law). Consequently, describing the neural and behavioral mechanisms of perceived causality is necessary, but not sufficient, to understanding human causal knowledge.

Studies of human causal knowledge need to address the question of how perceptual representations of the spatial and temporal cues of causal events give rise to or are influenced by higher-order causal reasoning. Since language is one of the distinctive cognitive functions of humans for referring to higher-order representations, it must be closely related to causal knowledge as an inferential process. However, research on causal reasoning rarely addresses the issue of the relation between language and perceived causality. Moreover, the literature does not report how such integration is implemented in the brain. 
In this article, we discuss how the study of linguistic representations of causal events can introduce new perspectives on the representation of causal knowledge. We initially describe and differentiate two research lines that account for causal representation from a psycholinguistic view: the use of causal knowledge in text processing (e.g., syntactic resolutions) and linguistic representations of external causal events. We develop this second approach with the purpose of establishing how linguistic representations of causation can be integrated with perceived and judged causality. This subsequent analysis sets the basis for the third section of the article in which we discuss our work on the existence of mechanisms integrating sensory and semantic representations of causal events and their neural interaction in the frontal lobe.

\section{CAUSALITY IN SENTENCE AND TEXT COMPREHENSION}

The notion of causality has been used to investigate different syntactic and textual aspects of language representation (Corrigan, 2001; Long \& De Lay, 2000; Rudolph \& Forsterling, 1997; Simner \& Pickering, 2005; Stewart \& Pickering, 2000). At a sentence level (e.g., "Peter called John because he wanted to know the truth"), readers attend to the participant of the sentence ("Peter") as biased by the implicit causality encoded by the preposition ("because") that in turn leads the reader to complete the task of assigning this role to an ambiguous pronoun ("he") (Long \& De Lay, 2000; Stewart \& Pickering, 2000).

At a textual level, the notion of causality has been used to address how readers represent texts by reasoning about the causal events to which parts of the text refer (Mason \& Just, 2004; Noordman \& Vonk, 1998; Wolfe, Magliano, \& Larsen, 2005). Even though this research considers the representation of causal events and how cognitive processes operate over these representations, the research focuses on other aspects of language processing such as the resolution of ambiguities or sentence and global text comprehension. Moreover, this research embeds language processing within higher cognitive functions (e.g., memory, syntactic transformations and semantic representations) but does not relate it to lower functions such as visual perception.

For example, the syntactic-discursive approach does not consider sensory inputs other than linguistic strings. Causal representations are necessary to solve syntactic ambiguities or to comprehend texts by inferring causes and consequences (Halldorson \& Singer, 2002; Singer \& O'Connell, 2003; Valencia-Laver \& Light, 2000; Wiley \& Myers, 2003), but the traditional psycholinguistic view of causality in text comprehension does not address whether such representations are exclusively semantic or require sensory-driven representations. That is, traditionally, sensory representations and semantic processing have been assumed independent from 
each other and located in different cognitive (i.e., cerebral) modules. Nevertheless, new linguistic and biological evidence suggests that semantic and sensory areas interact in higher-order language processing. Therefore, linguistic processing of causality might imply this perceptual-semantic relation.

\section{LINGUISTIC DESCRIPTIONS OF PERCEIVED CAUSALITY: MAPPING LINGUISTIC CAUSALITY ONTO THE VISUAL WORLD}

In addition to the impact of causal relations on resolving pronoun ambiguities, event relations, and other textual issues, the expressions that people use to describe causal events have also been shown to reflect aspects of their interpretations of the nature of the causal interaction. When participants observe causal events, they refer to them by using specific and distinguishable sets of linguistic structures (Hovav, Doron, \& Sichel, 2010; Song \& Wolff, 2003; Wolff, Klettke, Ventura, $\&$ Song, 2005). For example, after seeing a car striking a tree and the tree falling down, viewers usually describe the event using structures like "the car knocked down the tree" or "the car caused the tree to fall". In contrast, when a car strikes a tree and the tree falls on a house, we would not say "the car damaged the house" but rather "the car caused the house to be damaged" to indicate the indirect nature of the causal relation.

The literature that addresses these types of linguistic-perceptual relationships examines how syntactic structures describe external events or objects (Altmann \& Kamide, 2004). In causality research, scientists are examining the linguistic structures people use to describe specific instances of causal events (Wolff, 2003, 2007; Wolff, et al., 2005; Wolff \& Song, 2003; Wolff \& Zettergren, 2002). The two most commonly studied syntactic structures that describe causal relations involve lexical and periphrastic sentences.

At the simplest level, perceptual causal events fall into two classes: direct and indirect. Wolff et al. (2005) used the force dynamic theory of causality to determine the perceptual cues that produce the differential linguistic encoding of these event classes. In a causal event, there is an affector and a patient, each represented with nouns in a sentence. For example, in the sentence "the car knocked down the tree," the nouns "car" and "tree" represent the affector and the patient, respectively. Direct causation is present if one of two conditions is met: (a) there is no intermediate entity between the affector and the patient, or (b) there is an intermediate entity but it acts as an enabler (e.g., a tool).

For example, in the event in which a car knocks down a tree, there is no intermediary. Thus, the force dynamic theory predicts that this event is judged as an example of direct causation and direct causal events are typically described with lexical causative structures (Wolff, 2003). On the other hand, in the event in which 
a car strikes a tree, the tree falls down and breaks a window, the event includes a non-enabling intermediary (the tree is not considered an enabler because the tree's fall is simply another cause in a causal chain rather than a tool used by the car to break the window). Consequently, it is indirect with respect to the car and the window. Participants, tend to use periphrastic causatives such as "the car caused the window to break" to refer to this event (Wolff, 2003).

The work of Wolff and his collaborators raises two important issues with regard to the relation between perceived causality and linguistic coding. First, although causal reasoning and perceived causality are generally considered independent processes in the cognitive system, Wolff et al. (2005) clearly show the existence of a relation between them. Second, they describe the linguistic structures people use to refer to both direct and indirect events. The distinctiveness between the lexical and periphrastic semantic representation of causality has led us to integrate the research on neural mechanisms of perceived and judged causality with higherorder linguistic processing of causal events.

\section{NEURAL BASIS OF CAUSAL PROCESSING}

In the biological research on causality, Michotte's launching effect continues to be a powerful tool to address how the cognitive system processes causal information (Thines, Costall, \& Butterworth, 1990). The effect involves a shape (often a square or circle) moving across a display on a straight path until it is contiguous to a static shape at which point the first shape stops moving and the second shape begins moving along the same trajectory, away from the first shape (Figure 1). Participants observe variations on this basic launch and are asked to either judge whether or not the visual depiction represents a causal event, a causal judgment task, or simply focus their attention on the stimulus without explicitly categorizing the event as causal, a task often called causal perception because the causal aspect of the stimulus is assumed to be automatically and implicitly perceived, not explicitly judged.

With subtle variations, both the direct launching event and the judgment/ perception task constitute the standard paradigm that has been used in identifying the neural basis of visual causal representation (Blakemore et al., 2001; Fonlupt, 2003; Fugelsang \& Dunbar, 2005; Fugelsang, Roser, Corballis, Gazzaniga, \& Dunbar, 2005). For example, Blakemore et al. (2001) used fMRI to identify which temporal, parietal and occipital regions of the brain were more active during the perception of visual launching events (when compared to non-causal events). Such activations were deemed independent from attentional processes and led them to conclude that perception of causal events is an automatic process driven by the visual system. In a more specific effort to neurally dissociate inferential or judged 


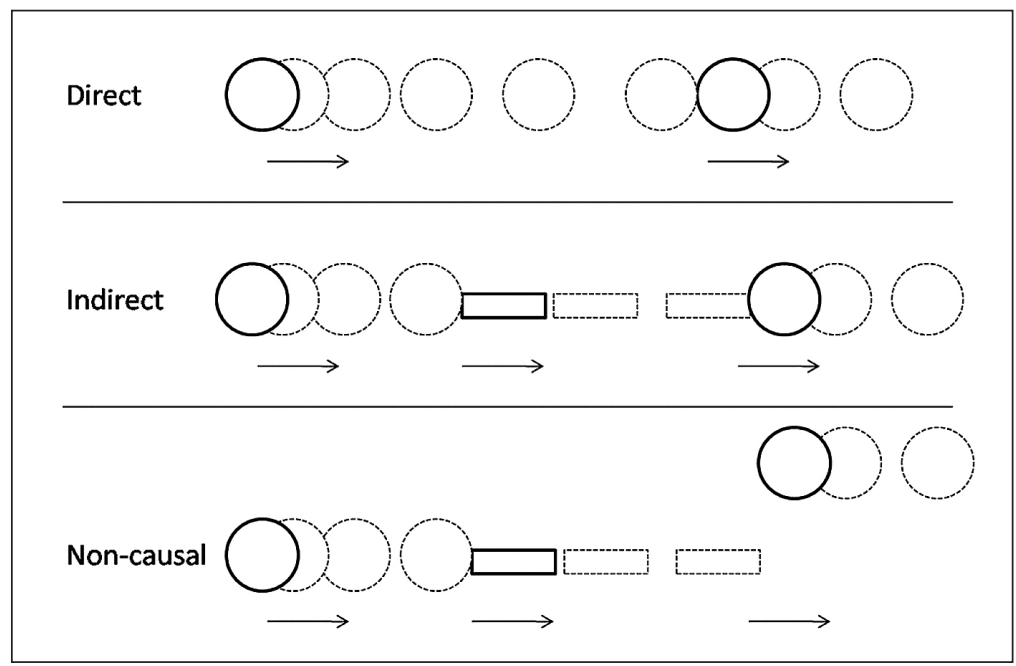

Figure 1. Michottean direct (top), indirect (middle) causal, and non-causal (below) animations. The direct and indirect causal animations show spatiotemporal contiguities between the affector and the effector whereas the non-causal animation only shows temporal contiguity.

causality from perceived causality, Fonlupt (2003) reanalyzed the data reported by Blakemore et al. (2001) and found bilateral activation in the superior frontal gyrus during the causal judgment task. Fonlupt suggested that two different modules process causal information. Initially, the visual system is wired to perceive the causal structure of a stimulus whereas the participation of the superior frontal gyrus elucidates whether a "causal-candidate stimulus" is or is not causal.

Fonlupt's (2003) results suggest an additional interpretation. As stated above, a causal judgment task includes a verbal instruction of the form "judge whether the event is or is not causal". It has been hypothesized that the spatiotemporal structure of visual causal events has given rise to a unique linguistic label (i.e., causation) and its associated semantic (i.e., categorical) representation (Young \& Sutherland, 2009). Consequently, the semantic representation of the verbal instruction "judge an event as causal" may drive the frontal cortex to integrate posterior cortical information with mnemonic information associated with the textual directive. In other words, in Blakemore's causal detection task the brain automatically detected the spatiotemporal contiguities of the causal event but the frontal neural activity associated with the semantic representation of the verbal instruction could have given rise to a higher-order causal representation. 


\section{NEURAL REPRESENTATION OF SPATIOTEMPORAL CONTIGUITIES OF CAUSAL EVENTS}

Perceived causality offers a finer level of granularity of causal events in terms of their spatiotemporal structure (Choi \& Scholl, 2004; Thines et al., 1990; Young, Rogers, \& Beckmann, 2005). For example, the cognitive system seems not only to perceive two balls colliding as a "gestalt" but also to detect two basic contiguities: the spatial contact of the balls and whether there was a delay between the action of the affector (the first ball) and that of the patient (the second ball). Manipulation of the spatiotemporal properties of a visual causal display permits the assessment of the sensory information that is critical for the perception of causality and for the prediction of causal events (Young et al., 2005). This manipulation is even more useful when identifying the neural basis of direct causal events. By manipulating the spatiotemporal dynamics of direct launching events, Fugelsang et al. (2005) reported specialized neural regions that participate in detecting causality in the absence of an explicit causal judgment task. Participants in their study observed launching events with a temporal delay or a spatial gap, and reported the direction of the objects' movements. Despite using a simple detection task, Fugelsang et al. found frontal lobe activations as well as specific posterior activity for the spatiotemporal components of perceived causality.

The work of Blakemore (2001), Fonlupt, (2003), and Fugelsang et al. (2005) identifies three distinctive characteristics of the neural underpinnings of causal perception and judgment. First, posterior areas of the brain might have differential participation in detecting the spatiotemporal contiguities of causal events (Figure 2). The right inferior parietal lobule seems to be specific to detecting the degree of temporal contiguity of the stimulus whereas the right middle temporal gyrus might detect the degree of spatial contiguity. Second, perception of causal events seems to involve frontal-lobe-driven processing. Specifically, the right rostrolateral prefrontal cortex (RLPFC), the middle dorsolateral prefrontal cortex (midDLPFC), and the right premotor cortex appear to participate in detecting causal collisions. Third, causal judgment might require integrating the spatiotemporal features of the causal animations and mnemonic causal representations (elicited by the linguistic representation of the task instruction) to produce a response. In the following section, we discuss findings from our research program that expand upon how different areas of the prefrontal cortex and the premotor cortex are associated with language-driven cognitive control in causal judgment. 


\section{THE LEXICAL AND PERIPHRASTIC SEMANTIC CAUSAL REPRESENTATION AND THE SPATIOTEMPORAL INTEGRATION IN THE PREFRONTAL AND PREMOTOR CORTICES}

Unlike causal perception, causal judgment is a controlled (i.e., goal-oriented) task. Previous research has indicated that a task involving cognitive control recruits activity in the prefrontal cortex, and this activity extends to the dorsal premotor area. This cumulative evidence comes from neuropsychological studies (Alexander, Stuss, Picton, Shallice, \& Gillingham, 2007; Badre \& D'Esposito, 2009; Baym, Corbett, Wright, \& Bunge, 2008; Benke, Delazer, Bartha, \& Auer, 2003; Chudasama \& Robbins, 2006; Clark, Cools, \& Robbins, 2004; Di Pellegrino, Ciaramelli, \& Ladavas, 2007), experimental brain damage (Chudasama, Baunez, \& Robbins, 2003), animal research (Cheatwood, Corwin, \& Reep, 2005; Cheatwood, Reep, \& Corwin, 2003), imaging studies (Badre \& Wagner, 2004; Egner \& Hirsch, 2005; Goghari \& Macdonald, 2009; Lie, Specht, Marshall, \& Fink, 2006; Sohn, Albert, Jung, Carter, \& Anderson, 2007), and computational models (Cohen, Braver, \& O'Reilly, 1996; Frank, Loughry, \& O’Reilly, 2001; Hazy, Frank, \& O’Reilly R., 2007). However, current data suggest that the subdivisions of the prefrontal areas do not perform a homogeneous role in cognitive control. Several theories have been proposed to account for these data, and these theories predict and inform the participation of the frontal subdivisions in causal judgment. By manipulating the linguistic instructions that participants must follow in experimental conditions, we have identified activity in four different regions of the rostro-caudal frontal axis during causal judgment tasks: the mid-DLPFC, the dorsal premotor cortex (PMd), the ventrolateral prefrontal cortex (VLPFC), and the RLPFC (Figure 2). In our study (Limongi Tirado, Habib, Young, \& Reinke, 2011), participants read either a lexical causative or a periphrastic causative verbal instruction followed by one of three types of dynamic stimuli (direct causal, indirect causal, and non causal, Figure 1) upon which they made a causal judgment. Under the lexical and periphrastic conditions the midDLPFC and the PMd activated when participants judged direct and indirect events, respectively. However, when participants judged direct events during the lexical condition, the VLPFC activated whereas the RLPFC activated when they judged indirect events under the periphrastic condition. Based on these results, we believe that the mid-DLPFC and the PMd serve a common purpose in both the lexical and periphrastic conditions whereas the VLPFC and the RLPFC subserve specific language-driven task demands. 


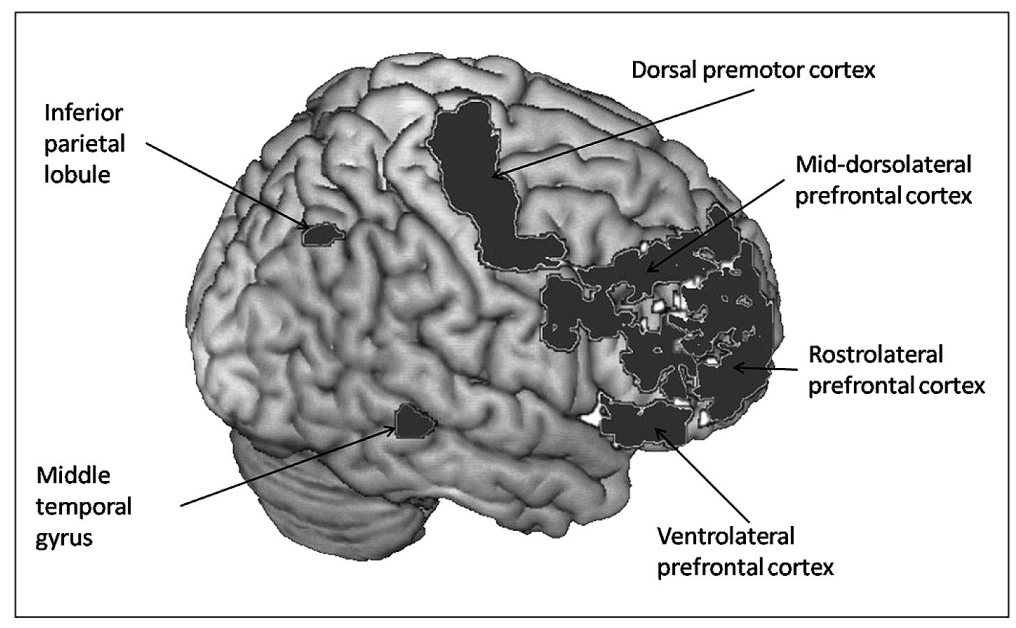

Figure 2. The division of labor between detecting the spatiotemporal structure of visual causal events (parietal and temporal areas) and integrating such structure in a causal gestalt (premotor and prefrontal areas).

\subsection{The mid-DLPFC}

The mid-DLPFC, a region lying between the posterior dorsolateral prefrontal cortex and the rostrolateral prefrontal area, has been proposed as supporting working memory functions in the cognitive monitoring of flexible decision making processes (Petrides, 2000). One such process is causal judgment, and a candidate role of the mid-DLPFC in that process is the refreshing of semantic and sensory information necessary for further processing - the refresh hypothesis (Badre \& Wagner, 2004). The refresh hypothesis is consistent with the fact that the prefrontal cortex seems to specialize in holding and contrasting semantic and visual representations (Herd, Banich, \& O’Reilly, 2006; Miller, 2000; Miller \& Cohen, 2001; Ullman, 2004). In the case of causal judgment, our data suggest that the sensory information (i.e., temporal and spatial contiguities) would come from the parietal and temporal areas and that the semantic information would be the active representation elicited by either the lexical or periphrastic linguistic instruction. Thus, while evaluating (i.e., judging) visual causation, activity in the mid-DLPFC would serve to actively maintain both the abstract causal representation elicited by the visual stream and the semantic representation elicited by the lexical or periphrastic linguistic instruction. 


\subsection{The PMd}

Although causal perception engages the PMd, both lexical and periphrastic semantic representations of causality are associated with the engagement of this region during causal judgment tasks. The premotor engagement arises, however, under two different conditions: when the task demands high cognitive effort (during the lexical condition) or when it demands a high level of abstraction (during the periphrastic condition). Because the PMd seems to execute concrete stages of the decision making process (Badre \& D'Esposito, 2009) as preparatory responses and in the processing of spatial information (Schubotz, Anwander, Knösche, Von Cramon, \& Tittgemeyer, 2010), it is not surprising that the PMd area subserves both roles during causal judgment (Limongi Tirado et al., 2011). Yet, this hypothesis needs further empirical support.

\subsection{The VLPFC}

Activity in the VLPFC, an area inferior from the mid-DLPFC, is associated with tasks that demand high cognitive effort and with the active selection of spatial and temporal information within short term memory (Petrides, 2005). Behavioral data suggest that the semantic representation of lexical causative structures demands higher effort in causal judgment than does the periphrastic causative structures (Limongi Tirado, 2008) whereas imaging data reveal that the VLPFC is more active during the lexical condition than during the periphrastic condition (Limongi Tirado et al., 2011). We believe that the VLPFC participates in the active selection of spatial and temporal information projected from the temporal/parietal areas within short term memory during causal judgment. Abe et al. (2007) have proposed that in some tasks the activity of the VLPFC engages coordinated activity with the pre-PMd and the mid-DLPFC. Furthermore, Petrides (2000) has reported that the temporal and parietal regions communicate spatial and temporal information to the inferior part of the mid-DLPFC through the posterior DLPFC. Therefore, it would not be surprising that the semantic representation of the instruction "judge whether the orange ball moves the purple ball", drives the coordinated activity between the VLPFC and the mid-DLPFC in interpreting the spatiotemporal contiguities detected in posterior areas (Limongi Tirado et al., 2011).

\subsection{The RLPFC}

Located in the most anterior part or the prefrontal cortex, the RLPFC sustains 
representations of higher-order relational complexity (Christoff, Keramatian, Gordon, Smith, \& Madler, 2009). In causal judgment, the semantic representation of the periphrastic instruction "judge whether the orange ball causes the purple ball to move" would relate to activity in the RLPFC when observers evaluate highly abstract representations of causality (e.g., indirect events). Moreover, this activity might overlap the activity in the same region associated with the ultimate and most abstract goal of the task, "making a decision", because the RLPFC also exerts a coordinating role over the mid-DLPFC (Petrides, 2005).

\section{CONCLUSIONS AND FURTHER DIRECTIONS}

Understanding the causal structure of the world is fundamental for controlling and predicting it. Philosophy, psychology, and psycholinguistics debate whether causal reasoning depends exclusively upon environmental stimuli or if it is influenced by language-mediated higher-order inferences. With modern technology such as fMRI combined with psycholinguistic experimental designs, we have been able to address the problem from a new perspective.

Behavioral research has accounted for the critical cues that human and non-human animals use to judge or discriminate an event as causal. The neurophysiological and psycholinguistic data support the hypothesis that perceived causality and linguistic descriptions of causal events might share common behavioral and neural mechanisms. Both perceptual and linguistic representations would encode the spatiotemporal structure of a causal event. However, whereas posterior areas of the brain would contribute by encoding the spatiotemporal properties of the stimuli, the linguistic representation of causality would drive the integration of the spatiotemporal cues in a causal gestalt. At this point in the process, the frontal lobe would participate.

Within this context, however, it is worth acknowledging that visual causal events are not the most complex form of causal reasoning. Perhaps the highest level of causal representation occurs during discourse processing (Halldorson \& Singer, 2002; Singer \& O'Connell, 2003; Valencia-Laver \& Light, 2000; Wiley $\&$ Myers, 2003). How does the relation between causal perception and higherorder causal reasoning contribute to causal inference at a discourse level? We have postulated that the linguistic and perceptual representations of causal events are not processed in a modular way but via functional connections in the brain. As the task becomes more discourse-oriented and thus more conceptual, there will be an increase in linguistic demands whereas sensory demands will decrease. A thorough understanding of the neural basis of causal representation requires knowledge of the neural underpinnings of discourse processing and how these might relate to those of causal perception and causal reasoning. 


\section{REFERENCES}

Abe, M., Hanakawa, T., Takayama, Y., Kuroki, C., Ogawa, S., \& Fukuyama, H. 2007. Functional coupling of human prefrontal and premotor areas during cognitive manipulation. J Neurosci, 27 (13), 3429-3438.

Alexander, M. P., Stuss, D. T., Picton, T., Shallice, T., \& Gillingham, S. 2007. Regional frontal injuries cause distinct impairments in cognitive control. Neurology, 68 (18), 1515-1523.

Altmann, G. T. M., \& Kamide, Y. 2004. Now you see it, now you don't: Mediating the mapping between language and the visual world. In J. M.Henderson \& F. Ferreira (Eds.), The interface of language, vision, and action (pp. 347-387). New York: Psychology Press.

Badre, D., \& D'Esposito, M. 2009. Is the rostro-caudal axis of the frontal lobe hierarchical? Nat Rev Neurosci, 10 (9), 659-669.

Badre, D., \& Wagner, A. D. 2004. Selection, integration, and conflict monitoring; assessing the nature and generality of prefrontal cognitive control mechanisms. Neuron, 41(3), 473-487.

Baym, C. L., Corbett, B. A., Wright, S. B., \& Bunge, S. A. 2008. Neural correlates of tic severity and cognitive control in children with tourette syndrome. Brain, 131 (Pt. 1), 165-179.

Benke, T., Delazer, M., Bartha, L., \& Auer, A. 2003. Basal ganglia lesions and the theory of fronto-subcortical loops: Neuropsychological findings in two patients with left caudate lesions. Neurocase, 9 (1), 70-85.

Blakemore, S. J., Fonlupt, P., Pachot-Clouard, M., Darmon, C., Boyer, P., Meltzoff, A. N., et al. 2001. How the brain perceives causality: An eventrelated fmri study. Neuroreport, 12 (17), 3741-3746.

Cheatwood, J. L., Corwin, J. V., \& Reep, R. L. 2005. Overlap and interdigitation of cortical and thalamic afferents to dorsocentral striatum in the rat. Brain Res, 1036 (1-2), 90-100.

Cheatwood, J. L., Reep, R. L., \& Corwin, J. V. 2003. The associative striatum: Cortical and thalamic projections to the dorsocentral striatum in rats. Brain Res, 968 (1), 1-14.

Choi, H., \& Scholl, B. J. 2004. Effects of grouping and attention on the perception of causality. Perception \& Psychophysics, 66 (6), 926-942.

Christoff, K., Keramatian, K., Gordon, A. M., Smith, R., \& Madler, B. 2009. Prefrontal organization of cognitive control according to levels of abstraction. Brain Research, 1286, pp. 94-105.

Chudasama, Y., \& Robbins, T. W. 2006. Functions of frontostriatal systems in cognition: Comparative neuropsychopharmacological studies in rats, monkeys and humans. Biol Psychol, 73 (1), 19-38.

Chudasama, Y., Baunez, C., \& Robbins, T. W. 2003. Functional disconnection 
of the medial prefrontal cortex and subthalamic nucleus in attentional performance: Evidence for corticosubthalamic interaction. J Neurosci, 23 (13), 5477-5485.

Clark, L., Cools, R., \& Robbins, T. W. 2004. The neuropsychology of ventral prefrontal cortex: Decision-making and reversal learning. Brain and Cognition, 55 (1), 41-53.

Cohen, J. D., Braver, T. S., \& O'Reilly, R. C. 1996. A computational approach to prefrontal cortex, cognitive control and schizophrenia: Recent developments and current challenges. Philos Trans R Soc Lond B Biol Sci, 351 (1346), 15151527.

Corrigan, R. 2001. Implicit causality in language: Event participants and their interactions. Journal of Language \& Social Psychology, 20 (3), 285-320.

Di Pellegrino, G., Ciaramelli, E., \& Ladavas, E. 2007. The regulation of cognitive control following rostral anterior cingulate cortex lesion in humans. J Cogn Neurosci, 19 (2), 275-286.

Egner, T., \& Hirsch, J. 2005. The neural correlates and functional integration of cognitive control in a stroop task. NeuroImage, 24 (2), 539-547.

Fonlupt, P. 2003. Perception and judgment of physical causality involve different brain structures. [Research report]. Cognitive Brain Research (17), 248-254.

Frank, M. J., Loughry, B., \& O’Reilly, R. C. 2001. Interactions between frontal cortex and basal ganglia in working memory: A computational model. Cogn Affect Behav Neurosci, 1 (2), 137-160.

Fugelsang, J. A., \& Dunbar, K. N. 2005. Brain-based mechanisms underlying complex causal thinking. Neuropsychologia, 43 (8), 1204-1213.

Fugelsang, J. A., Roser, M. E., Corballis, P. M., Gazzaniga, M. S., \& Dunbar, K. N. 2005. Brain mechanisms underlying perceptual causality. Cognitive Brain Research, 24 (1), 41-47.

Goghari, V. M., \& Macdonald, A. W., 3rd. 2009. The neural basis of cognitive control: Response selection and inhibition. Brain Cognition 71 (2). pp. 72-83.

Halldorson, M., \& Singer, M. 2002. Inference processes: Integrating relevant knowledge and text information. Discourse Processes, 34 (2), 145-161.

Hazy, T. E., Frank, M. J., \& O’Reilly R, C. 2007. Towards an executive without a homunculus: Computational models of the prefrontal cortex/basal ganglia system. Philos Trans R Soc Lond B Biol Sci, 362 (1485), 1601-1613.

Herd, S. A., Banich, M. T., \& O'Reilly, R. C. 2006. Neural mechanisms of cognitive control: An integrative model of stroop task performance and fmri data. Journal of Cognitive Neuroscience, 18 (1), 22-32.

Hovav, M. R., Doron, E., \& Sichel, I. 2010. Lexical semantics, syntax, and event structure. New York: Oxford University Press Inc.

Lie, C. H., Specht, K., Marshall, J. C., \& Fink, G. R. 2006. Using fmri to decompose the neural processes underlying the wisconsin card sorting test. 
NeuroImage, 30 (3), 1038-1049.

Limongi Tirado, R. 2008. Linguistic top-down modulation of causal perception. US: ProQuest Information \& Learning.

Limongi Tirado, R., Habib, R., Young, M. E., \& Reinke, K. 2011. Higher-order visual causal representation in the prefrontal and premotor cortices. Paper presented at the 2011 Cognitive Neuroscience Society Annual Meeting.

Long, D. L., \& De Lay, L. 2000. Implicit causality and discourse focus: The interaction of text and reader characteristics in pronoun resolution. Journal of Memory \& Language, 42 (4), 545-570.

Mason, R. A., \& Just, M. A. 2004. How the brain processes causal inferences in text: A theoretical account of generation and integration component processes utilizing both cerebral hemispheres. Psychological Science, 15 (1), 1-7.

Miller, E. K. 2000. The prefrontal cortex and cognitive control. Nature Reviews Neuroscience, 1 (1), 59-65.

Miller, E. K., \& Cohen, J. D. 2001. An integrative theory of prefrontal cortex function. Annual review of neuroscience, 24, 167-202.

Noordman, L. G. M., \& Vonk, W. 1998. Memory-based processing in understanding causal information. Discourse Processes, 26 (2/3), 191-212.

Petrides, M. 2000. The role of the mid-dorsolateral prefrontal cortex in working memory. Experimental Brain Research, 133 (1), 44-54.

Petrides, M. 2005. Lateral prefrontal cortex: Architectonic and functional organization. Philosophical Transactions of the Royal Society B: Biological Sciences, 360 (1456), 781-795.

Rudolph, U., \& Forsterling, F. 1997. The psychological causality implicit in verbs: A review. Psychological Bulletin, 121 (2), 192-218.

Schubotz, R. I., Anwander, A., Knösche, T. R., Von Cramon, D. Y., \& Tittgemeyer, M. 2010. Anatomical and functional parcellation of the human lateral premotor cortex. NeuroImage, 50, 396-408.

Simner, J., \& Pickering, M. J. 2005. Planning causes and consequences in discourse. Journal of Memory and Language, 52 (2), 226-239.

Singer, M. M., \& O'Connell, G. 2003. Robust inference processes in expository text comprehension. European Journal of Cognitive Psychology, 15 (4), 607-631.

Sohn, M. H., Albert, M. V., Jung, K., Carter, C. S., \& Anderson, J. R. 2007. Anticipation of conflict monitoring in the anterior cingulate cortex and the prefrontal cortex. Proc Natl Acad Sci USA, 104 (25), 10330-10334.

Song, G., \& Wolff, P. 2003. Linking perceptual properties to the linguistic expression of causation. In M. Achard \& S. Kemmer (Eds.), Language, culture and mind (pp. 237-250). Stanford, CA: CSLI Publications.

Stewart, A. J., \& Pickering, M. J. 2000. The time course of the influence of implicit causality information: Focusing versus integration. Journal of Memory \& Language, 42 (3), 423-443. 
Thines, G., Costall, A., \& Butterworth, G. 1990. Michotte's experimental phenomenology of perception. Hillsdale, NJ: Lawrence Erlbaum Associates.

Ullman, M. T. 2004. Contributions of memory circuits to language: The declarative/procedural model. Cognition, 92 (1-2), 231-270.

Valencia-Laver, D. L., \& Light, L. L. 2000. The occurrence of causal bridging and predictive inferences in young and older adults. Discourse Processes, 30 (1), 27-56.

Wiley, J., \& Myers, J. L. 2003. Availability and accessibility of information and causal inferences from scientific text. Discourse Processes, 36 (2), 109-129.

Wolfe, M. B. W., Magliano, J. P., \& Larsen, B. 2005. Causal and semantic relatedness in discourse understanding and representation. Discourse Processes, 39 (2\&3), 165-187.

Wolff, P. 2003. Direct causation in the linguistic coding and individuation of causal events. Cognition, 88 (1), 1-48.

Wolff, P. 2007. Representing causation. Journal of Experimental Psychology: General, 136 (1), 82-111.

Wolff, P., \& Song, G. 2003. Models of causation and the semantics of causal verbs. Cogn Psychol, 47 (3), 276-332.

Wolff, P., \& Zettergren, M. 2002. A vector model of causal meaning. In W. D. Gray \& C. D. Schunn (Eds.), Proceedings of the twenty-forth annual conference of the cognitive science society (pp. 944-949). Hillsdale, NJ: Erlbaum.

Wolff, P., Klettke, B., Ventura, T., \& Song, G. 2005. Expressing causation in english and other languages. In W.-K. Ahn, R. L. Goldstone, B. C. Love, A. B. Markman \& P. Wolff (Eds.), Categorization inside and outside the laboratory: Essays in honor of douglas l. Medin (pp. 29-48). Washington, DC: American Psychological Association.

Young, M. E., \& Sutherland, S. 2009. The spatiotemporal distinctiveness of direct causation. Psychonomic Bulletin and Review 16 (4), pp. 729-735.

Young, M. E., Rogers, E. T., \& Beckmann, J. S. 2005. Causal impressions: Predicting when, not just whether. Memory \& Cognition, 33 (2), 320-331. 